\title{
Toxicological assessment of multi-walled carbon nanotubes in vitro: potential mitochondria effects on male reproductive cells
}

\author{
Cheng $\mathrm{Xu}^{1,2, *}$, Qian Liu ${ }^{1,2, *}$, Hui Liu ${ }^{1,2}$, Chunlan Zhang ${ }^{1,2}$, Wentao Shao ${ }^{1,2}$ and Aihua \\ Gu ${ }^{1,2}$ \\ ${ }^{1}$ State Key Laboratory of Reproductive Medicine, Institute of Toxicology, Nanjing Medical University, Nanjing, China \\ ${ }^{2}$ Key Laboratory of Modern Toxicology of Ministry of Education, School of Public Health, Nanjing Medical University, Nanjing, \\ China \\ *These authors have contributed equally to this study, and they should be regarded as joint first authors \\ Correspondence to: Aihua Gu, email: aihuagu@njmu.edu.cn \\ Keywords: multiwalled carbon nanotubes; in vitro; male reproduction; spermatocyte; mitochondria; Pathology Section \\ Received: April 05, $2016 \quad$ Accepted: May 23, $2016 \quad$ Published: May 29, 2016
}

\section{ABSTRACT}

Multi-walled carbon nanotubes (MWCNTs) have been widely used in many fields and were reported to cause reversible testis damage in mice at high-dose. However the reproductive effects of low dose MWCNTs remained elusive. Herein, we used the mice spermatocyte cell line (GC-2spd) to assess the reproductive effects of MWCNTs. Size distribution, zeta potential, and intensity of MWCNTs were characterized. A maximal concentration of $0.5 \mu \mathrm{g} / \mathrm{mL}$ MWCNTs was found to be nonlethal to GC-2spd. At this dose, cell cycles and the ROS levels were in normal status. We also found MWCNTs accumulated in mitochondria, which caused potential mitochondrial DNA damage in spermatocyte. Furthermore, the expression level of mitochondria-related genes, the oxygen consumption rate, and cellular ATP content were declined compared to controls, even at the nonlethal dose. Our results suggested for the first time that, in germ cells, mitochondrion was a cellular organelle that accumulated MWCNTs.

\section{INTRODUCTION}

Carbon nanotubes (CNTs) are allotropes of carbon with large length-to-diameter ratio. In general, CNTs are categorized as single-walled CNTs (SWCNTs) and multi-walled CNTs (MWCNTs). MWCNTs have recently been applied in wide fields such as composite material development, medical contrast imaging agents, and drug delivery [1-3]. However, the effects of MWCNTs on human health are still unclear due to limit epidemiologic information. Therefore, in vitro and in vivo data are useful. Our study focused on the effect of low dose of MWCNTs exposure on male reproductive system. To our knowledge, no similar study has ever been reported before. Although MWCNTs were considered safe for use [4], the potential toxicity has been reported in several recent studies [57], mainly on the genotoxicity and carcinogenicity [810]. Meanwhile, researchers paid more attentions on the biological effects of the MWCNTs, and serial low concentrations of MWCNTs including $12.5 \mu \mathrm{g} / \mathrm{mL}$ [7], 5 $\mu \mathrm{g} / \mathrm{mL}$ [11], $5 \mathrm{mg} / \mathrm{mL}$ [12], $2.5 \mu \mathrm{g} / \mathrm{mL}$ [13] for different kinds of cell lines were adopted. A recent study evaluating the safety of MWCNTs for health risk with in vivo dose (i.t. administration, $1 \mathrm{mg} / \mathrm{kg}$ b.w., in rats) and in vitro dose (exceedingly low concentration of $1 \mu \mathrm{g} / \mathrm{mL}$, in human A549 pneumocytes) still showed potential pulmonary toxic effects [14]. Compared with all those doses used, $1 \mu \mathrm{g} / \mathrm{mL}$ MWCNT was the lowest concentration in all the studies ever reported.

However, little information was available on the male reproductive hazards of MWCNTs exposure. One previous study found that MWCNTs partially damaged seminiferous tubules with increasing ROS levels and cytotoxicity [15]. Although the repeated carbon nanotube administrations in male BALB/c mice seemed not impair fertility, while the intravenously injection of $5 \mathrm{mg} / \mathrm{kg}$ nanotubes still cause oxidative stress and reversible testis damage [15]. Actually, the reproductive effects of lowdose MWCNTs are more important than that of highdose MWCNTs, which remains unclear yet. In this study, the GC-2spd cell line, which derived from immortalized mouse spermatocyte, was used as an available in vitro 
model of germ cells, to address two important and challenging issues: (i) The potential reproductive effects of nonlethal-dose MWCNTs exposure, and (ii) an effectively in vitro assay to evaluate the potential reproductive effects, and the in vitro sensitive markers as well.

\section{RESULTS}

\section{Characterization of MWCNTs}

The characteristics of MWCNTs in double distilled water and cell culture medium were showed in Figure 1A. The size of MWCNTs appearing like approximate tubulose was demonstrated by TEM (Figure 1B), which was consist with the specification sheet. Because serum proteins have better dispersion property for MWCNTs [16], the particle size distribution (Figure 1C) showed that MWCNTs had a lesser particle-size distribution of approximate $180 \mathrm{~nm}$ in culture medium than about $300 \mathrm{~nm}$ in double distilled water. The zeta potential of MWCNTs was $-10.9 \pm 0.4$ $\mathrm{mV}$ in cell culture medium, and $-28.3 \pm 0.2 \mathrm{mV}$ in double distilled water, respectively.

\section{The effects of MWCNTs on GC-2spd cell viability}

GC-2spd cells were treated with various concentrations of MWCNTs $(0,0.05,0.25,0.5,1$, and $5 \mu \mathrm{g} / \mathrm{mL}$ ) for $24 \mathrm{~h}$ before cell viability detection. Considering that nanoparticles may influence the accuracy of cell viability analysis [17], we used both alamarBlue method and xCELLigence approaches to obtain and confirm the cell viability results. Compared with control, no remarkable cytotoxicity was observed in GC-2spd cells treated with $0.5 \mu \mathrm{g} / \mathrm{mL}$ of MWCNTs for $24 \mathrm{~h}$ (Figure 2A, 2B, Figure S1), suggesting that concentration was a relatively safe dose, which was double confirmed by the following data: compared with control, the key markers of cell cycle and cell apoptosis were determined by western blotting (Figure 2C), and neither impair cell cycle (Figure 2D) nor cell apoptosis (Figure 2E) were changed in the cells treated with $0.5 \mu \mathrm{g} / \mathrm{mL}$ of MWCNTs. Furthermore, we did not find increased ROS level in GC2 spd cells treated with the dose of $0.5 \mu \mathrm{g} / \mathrm{mL}$ (Figure $2 \mathrm{~F}$ ). Therefore, $0.5 \mu \mathrm{g} / \mathrm{mL}$ was considered as a non-lethal dose of MWCNTs to GC-2spd cell viability.

\section{MWCNTs accumulated in mitochondria of GC- 2spd cell}

To explore the possible subcellular localization and potential adverse effect caused by MWCNTs, the uptake of MWCNTs was imaged by TEM, which showed that, MWCNTs accumulated in the mitochondria of GC-2spd cell (Figure 3A). We then detected the potential effect on mitochondria by long PCR approach [18] and found that the nonlethal-dose MWCNTs did not damage nuclear DNA (nDNA) genome, but increased mitochondrial DNA (mtDNA) lesions compared to control group (Figure 3B, 3C). Furthermore, we measured fluorescence intensity of mitochondria itself by stain with Mito-tracker Green dye, some mitochondria lost the green fluorescence, which was different from the control group (Figure 3D, 3E).

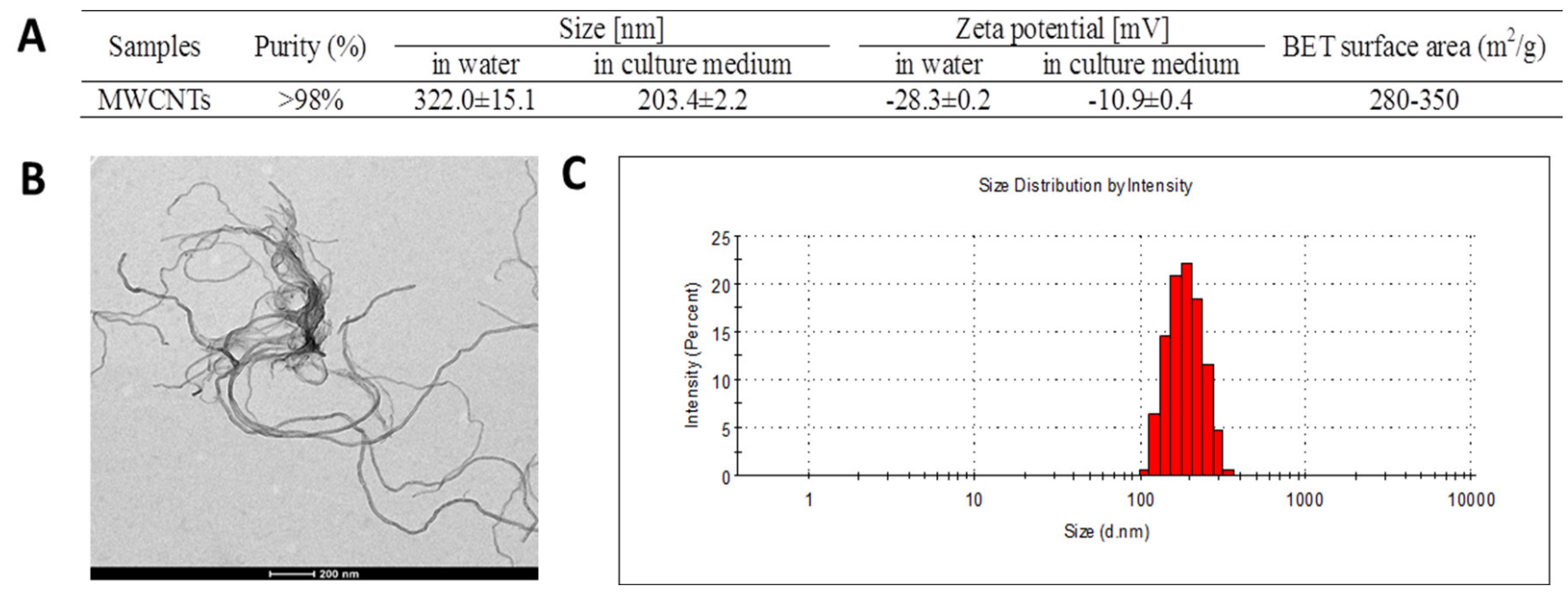

Figure 1: Characterization of MWCNTs. A. General characteristic and particle-size and zeta potential of MWCNTs in water and in cell culture medium. B. TEM image of MWCNTs, bar $=200 \mathrm{~nm}$. C. Particle-size distribution of MWCNTs prepared in cell culture medium. 

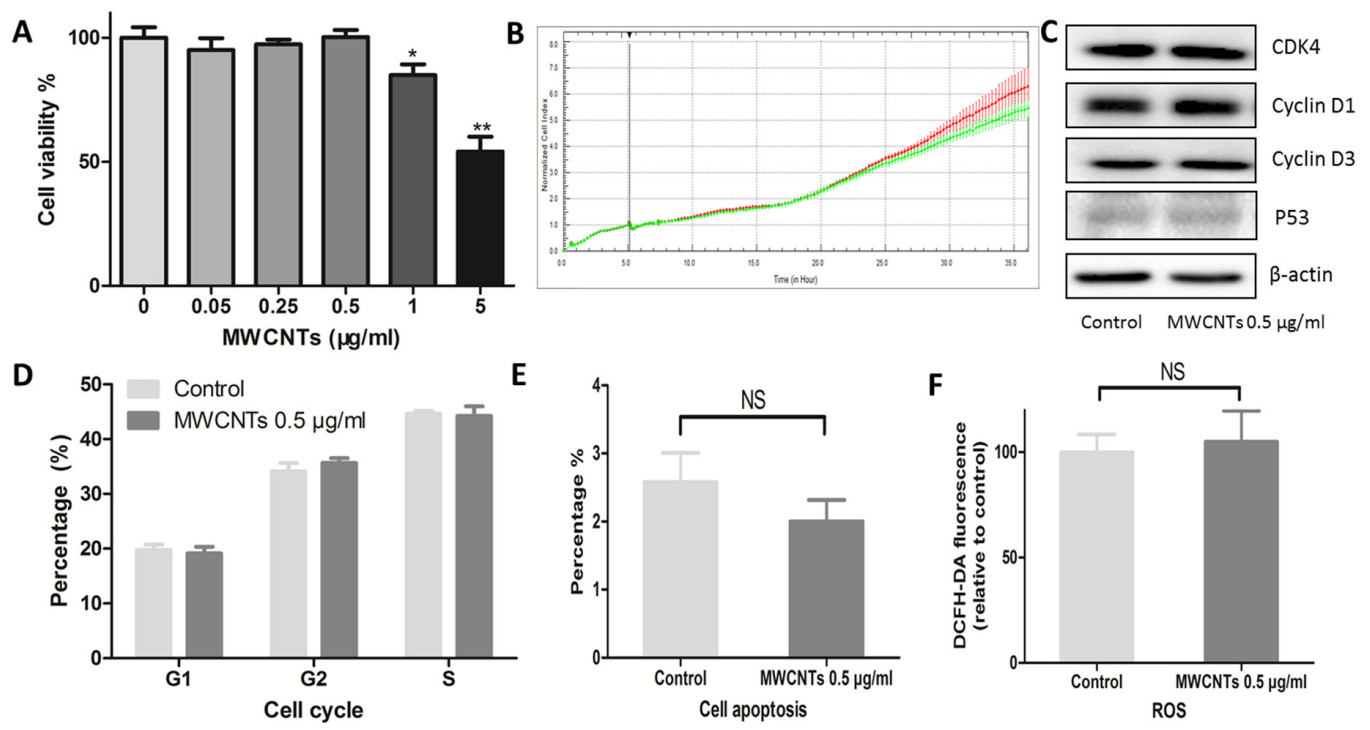

Figure 2: Cytotoxic responses of GC-2spd cells to MWCNTs. A. Viability of GC-2spd cells treated with different concentrations of MWCNTs for $24 \mathrm{~h}$ was measured using alamarBlue method. B. Viability of GC-2spd cells was examined by xCELLigence approach. The red and green line represent viability of control and $0.5 \mu \mathrm{g} / \mathrm{mL}$ MWCNTs treated, respectively. C. GC-2spd cells were incubated with MWCNTs $(0.5 \mu \mathrm{g} / \mathrm{mL})$ for $24 \mathrm{~h}$, the expression levels of CDK4, Cyclin D1, Cyclin D3, and P53 were determined by western blotting. D. Cell cycle profile were determined via PI staining using flow cytometer. E. After incubating with MWCNTs $(0.5 \mu \mathrm{g} / \mathrm{mL})$ for $24 \mathrm{~h}, \mathrm{GC}-2 \mathrm{spd}$ cells were were labelled with annexin V-FITC and DAPI using flow cytometer. F. The ROS levels were assessed by flow cytometer after MWCNTs exposure to GC-2spd cells and stained with DCFH-DA. These values were all expressed as means $\pm \mathrm{S}$.E. from three separate experiments. * represented as $P<0.05$, ** represented as $P<0.01$, NS represents no significance..

\section{A}

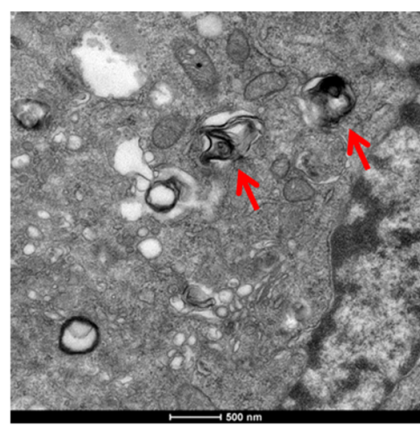

B

D

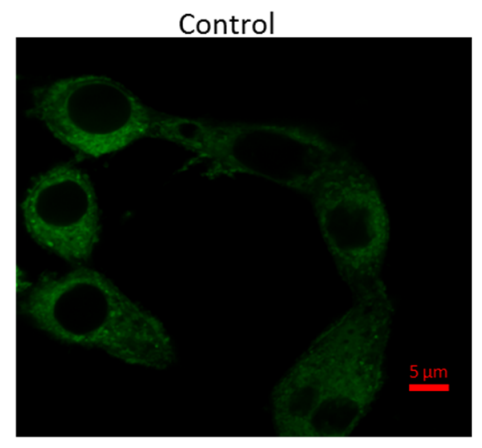

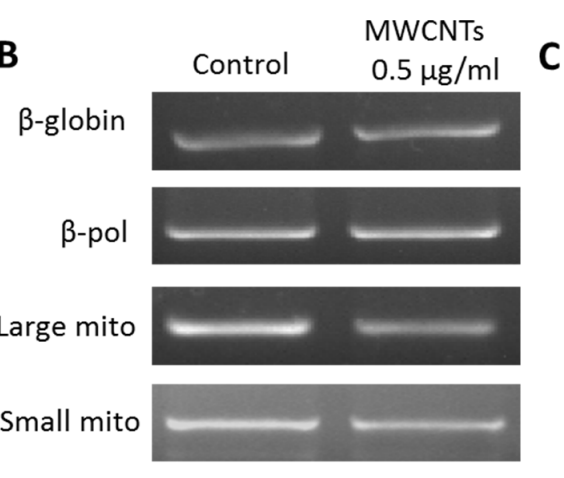

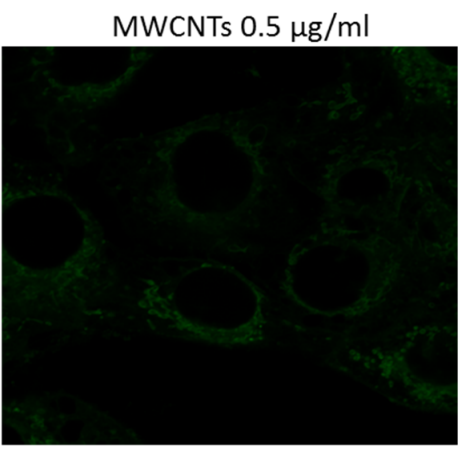

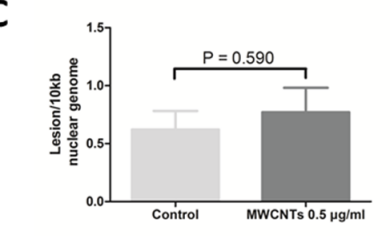

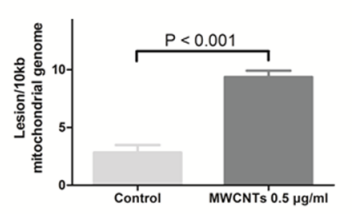

$\mathbf{E}$

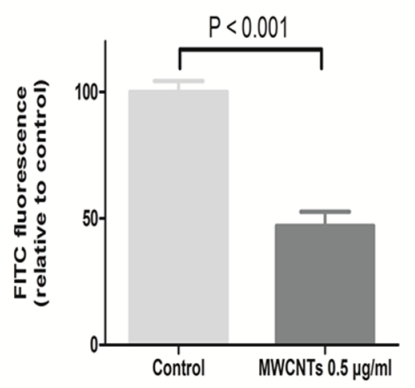

Figure 3: The effect of MWCNTs on the mitochondrial organelle in GC-2spd cells. A. TEM image showed a section of GC-2spd cells treated with MWCNTs. MWCNTs were accumulated in mitochondria of GC-2spd. B. The electrophoretic results of nuclear genomic DNA fragments (i.e. nDNA) and mitochondrial genomic DNA fragments (i.e. mtDNA) in GC-2spd cells. C. Quantitative levels of damage to nDNA and mtDNA of the GC-2spd cells between MWCNTs treatment and controls were shown on each right side. D. The labeling of mitochondria in GC-2spd cells. Confocal microscopy images showing the mitochondria amount and location after MWCNTs exposure. E. Quantitative levels of mitochondria fluorescence intensity. Each data was represented as the means \pm S.E. from three separate experiments. 


\section{The effects of MWCNTs on mitochondrial function of GC-2spd cell}

Oxygen consumption is at the upstream of intracellular ATP producing process, and oxygen consumption rate is one index of the mitochondrial function. We found that oxygen consumption rate of GC-2 spd cells decreased after MWCNTs treatment, with basal respiration rate significantly decreased $19.7 \%$ in 0.5
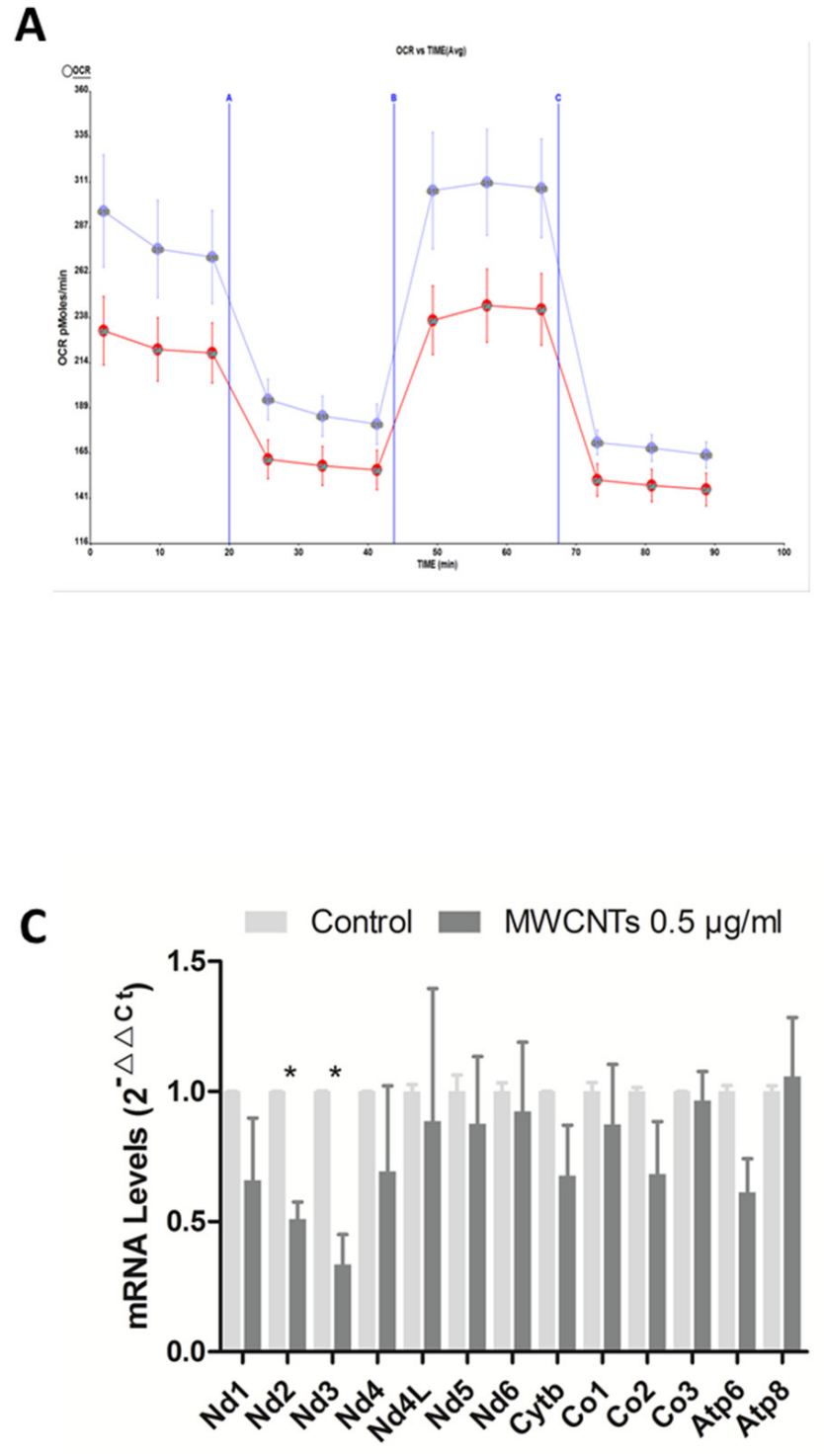

D

B
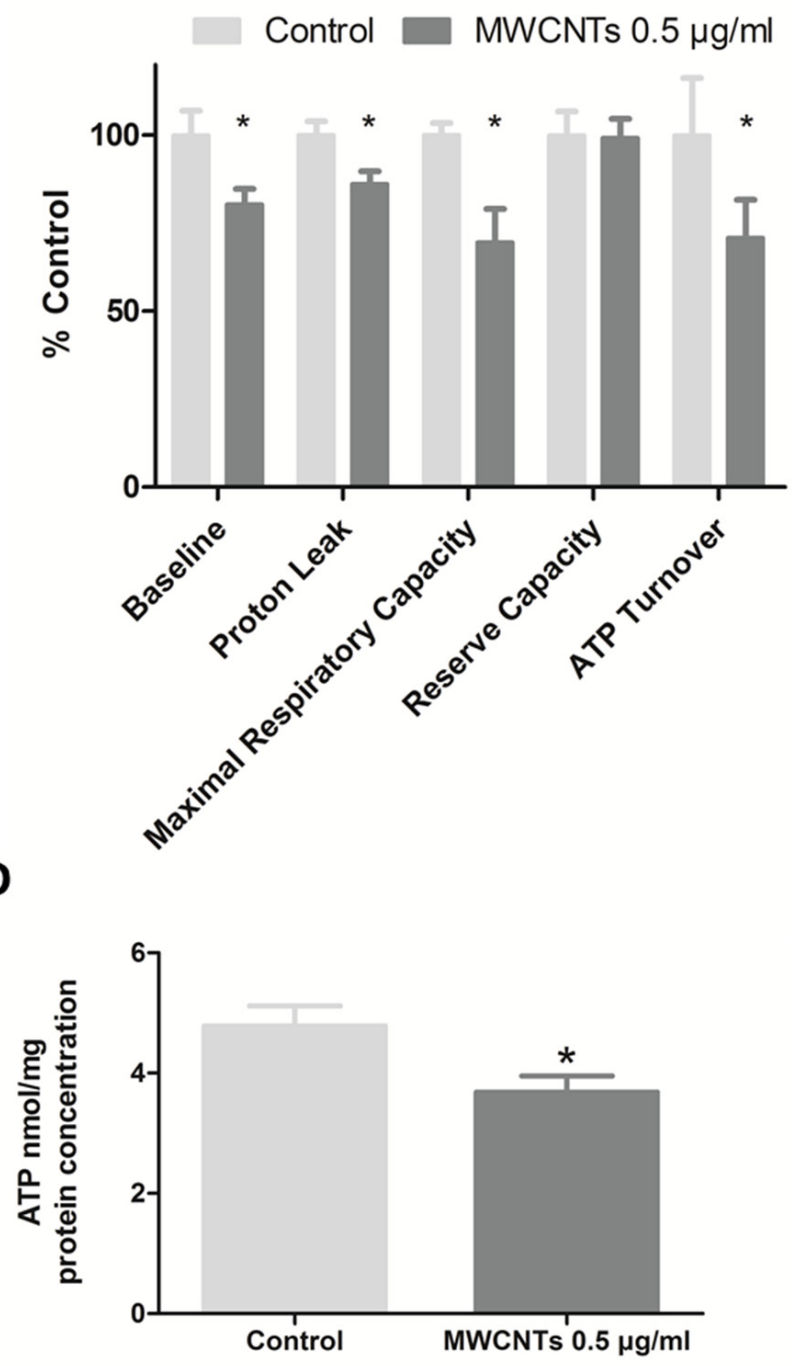

Figure 4: The mitochondrial functions after MWCNTs exposure to GC-2spd cells. A. Effects of MWCNTs on cellular OCR (oxygen consumption rate) were measured with the XF96 Extracellular Flux Analyzer. GC-2spd cells were respectively incubated with control or $0.5 \mu \mathrm{g} / \mathrm{mL}$ for $24 \mathrm{~h}$. Three inhibitors, oligomycin $(1 \mu \mathrm{M})$, FCCP $(0.75 \mu \mathrm{M})$ and antimycin A/rotenone $(0.5 \mu \mathrm{M}$ each $)$, were added at the different stage. The four periodes represent cellular endogenous rate, ATP-synthase-inhibited rate maximal uncoupled rate, and rotenone- and antimycin-A-inhibited rate. The results were normalized with cell protein levels. The blue and red lines respectively represent control and treated with $0.5 \mu \mathrm{g} / \mathrm{mL}$ MWCNTs. B. Quantitative histogram of OCR results. C. RT-qPCR analysis of the expression of genes between two groups in GC-2spd cells. The 18S rRNA was used as internal control. D. The ATP levels of GC-2spd cells detected by fluorescence reaction approach, adjusted by cell protein levels. *, $p$ value $<0.05$. Values were expressed as means \pm S.E. from three separate experiments. 
in mitochondrial respiratory chain on mammalia mitochondrial genome [19], and the expression level of these genes in GC-2spd cells treated with 0 and $0.5 \mu \mathrm{g} / \mathrm{mL}$ MWCNTs were also detected in our study. We found that the expression levels of MT-ND2 (mitochondria-NADH dehydrogenase subunit 2) and MT-ND 3 (mitochondriaNADH dehydrogenase subunit 3) declined in $0.5 \mathrm{ug} / \mathrm{mL}$ MWCNTs group compared to control (Figure 4C).

ATP, the molecular unit of currency of intracellular energy transfer, was mostly produced in mitochondria by aerobic respiration in cells. ATP content was detected in GC-2spd cells with non-lethal dose MWCNTs treatment, which was lower than control $(\mathrm{P}<0.05)$ after adjusted cellular protein concentration (Figure 4D).

\section{DISCUSSION}

In our study, we demonstrated firstly that, $0.5 \mu \mathrm{g} /$ mL MWCNTs, was the 'maximum' but 'non-lethal' dose without disturbing the health status of spermatocyte cell line. It had been 5 years since the MWCNTs was reported to penetrate blood-testis barrier and cause reproductive toxicity in mice at a high concentration $(5 \mathrm{mg} / \mathrm{kg}$, injections via the tail vein, described in a diagram, Figure 5) [15]. But little information about the effects of non-lethal dose MWCNTs on male reproduction was available so far due to lack of an effective in vitro model. Herein, GC-2spd cells were used to mimic spermatocyte to investigate the biological effects and genotoxicity of the non-lethal dose MWCNTs.

Previous studies reported that, respiratory epithelial cells exposed to MWCNTs at the concentration up to 24 $\mu \mathrm{g} / \mathrm{mL}$, the cell viability was not changed [20]. Similarly in macrophage like (THP-1), small airway epithelial (SAE), and intestinal (Caco-2/HT29-MTX) cells, the 'maximum' but 'nonlethal' dose of MWCNTs was all up to $10 \mu \mathrm{g} / \mathrm{mL}$ [21]. Herein, in GC-2spd cells, even at concentration of $1 \mu \mathrm{g} / \mathrm{mL}$, we still found the cell viability decreased $15 \%$ compared to control groups, suggesting the sensitivity of germ cells to damage by MWCNTs exposure.

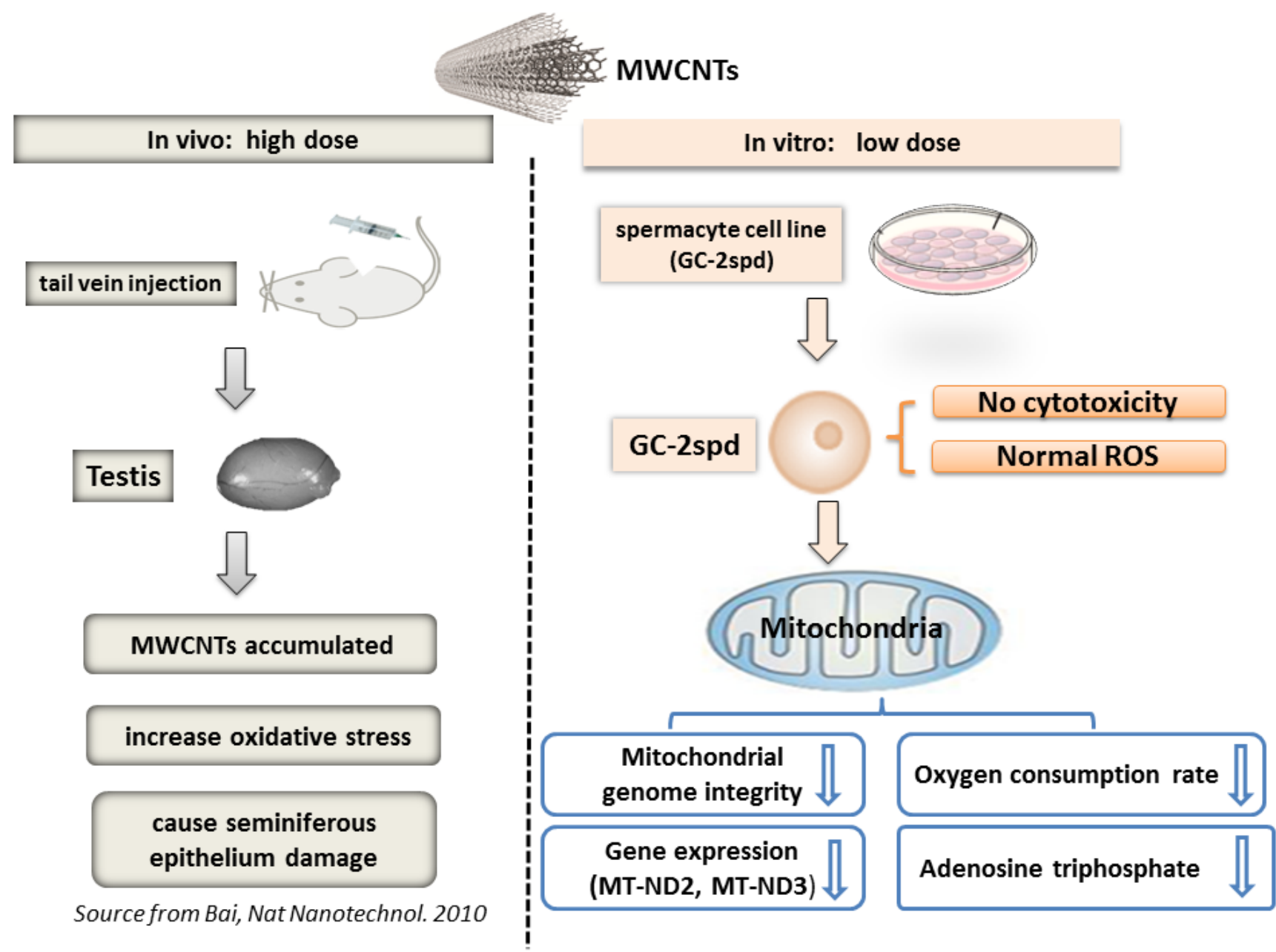

Figure 5: Schematic diagram showed the effects of MWCNTs on male reproduction. (in vivo with high dose, Source from Bai, Nat Nanotechnol. 2010) and (in vitro with low dose, The present study). 
Previous study also reported that, DNA damage occurred in mouse embryonic stem cells [22] treated with $100 \mu \mathrm{g} / \mathrm{mL}$ MWCNTs for $24 \mathrm{~h}$. Our data showed that, under a non-lethal dose of $0.5 \mu \mathrm{g} / \mathrm{mL}$ MWCNTs, mitochondrial DNA damage could already be observed before occurring of nDNA impairment in cells with health status, which indicated that mtDNA was more sensitive to MWCNTs compared with nDNA. The reasons might lie in three points: (1) lack of protective histones and proximity ROS originating from mitochondria [23]; (2) intact DNA damage repair in mitochondria and (3) accumulating of MWCNTs in mitochondria rather in nucleus. Therefore, the data indicated that mtDNA damage could be used as a sensitive biomarker superior to cell viability and nDNA status in the safety assessment of low doses MWCNTs exposure.

It is known that excessive increasing ROS levels may result in mitochondrial dysfunction [24] and even mtDNA lesion [25]. In this study, we measured ROS levels in GC-2spd cells after MWCNTs exposure for 24 $\mathrm{h}$, to explore whether ROS contributed to the mtDNA damage. We found the non-lethal dose did not increase ROS concentrations, in contrast to previous findings that MWCNTs could increase ROS levels in human small airway epithelial cells (exposure to $1.2 \mu \mathrm{g} / \mathrm{mL}$ ) [26]. It seemed that the ROS levels in cells treat with $0.5 \mu \mathrm{g} / \mathrm{mL}$ MWCNTs did not account for the mtDNA damage. The mtDNA lesion might be caused by "physical trauma" of MWCNTs, which was consisted with the phenomenon of the MWCNTs accumulation in mitochondria [27]. It was also observed in colon cells that, transport activity reduced without increasing ROS levels in MWCNTs exposure group [28], which according with our findings indirectly. Thus we speculated that the disturbed the mitochondrial structure may be the reason of mitochondiral dysfunction.

In conclusion, we applied spermatocyte cell as in vitro model to investigate the biological effects of the non-lethal dose of $0.5 \mu \mathrm{g} / \mathrm{mL}$ MWCNTs (summarized in a diagram, Figure 5). In this study, we found that, compared with the previous in vitro studies, germ cell (GC-2spd) was more sensitive to MWCNTs than other cell lines, as the maximum non-effective dose in cell vitality was much lower than that of other cells. We also found that, in germ cell (GC-2spd), mitochondria were more sensitive to MWCNTs than other organelles. Before cellular ROS and other cellular indicators changed, the related gene expressions and functions of mitochondria had altered in response to the extremely low dose MWCNTs exposure stress. Our study was also expected to shed light on the effect of low dose MWCNTs on male reproduction and provide several worthy information for MWCNTs safe application.

\section{MATERIALS AND METHODS}

\section{The characteristics and dispersion of MWCNTs}

MWCNTs (Sigma-Aldrich, 773840, $4.5 \mathrm{~nm} \pm 0.5$ $\mathrm{nm} \times 3 \sim 6 \mu \mathrm{m}$, Saint Louis, MO, USA) were characterized both in double distilled water and in complete cell culture medium contained with $10 \%$ fetal bovine serum (FBS, Sigma-Aldrich, Saint Louis, MO, USA). A JEOL JEM 2100 transmission electron microscope was used to image the MWCNTs. The MWCNTs size distributions and the zeta potential were analyzed in a Zetasizer Nano series model ZS (Brookhaven Instrument Corp.).

\section{Cell culture and MWCNTs treatment}

The immortalized cell lines GC-2spd(ts) produced by transformation with the SV40 large T antigen GC2spd was purchased from ATCC (CRL-2196, Manassas, VA, USA) and cultured at $37^{\circ} \mathrm{C}, 5 \% \mathrm{CO}_{2}$ with dulbecco's modified eagle medium, contained with $10 \%$ FBS, $100 \mathrm{U} /$ $\mathrm{mL}$ penicillin(Sigma-Aldrich, Saint Louis, MO, USA), and $100 \mathrm{mg} / \mathrm{mL}$ streptomycin(Sigma-Aldrich, Saint Louis, MO, USA). When the cell confluency reached $50 \%$, the freshly ultrasonic MWCNTs were added and incubated for $24 \mathrm{~h}$.

\section{Cell viability assay}

Cells were plated on 96-multi-well plates and administrated with different concentrations $(0,0.05,0.25$, $0.5,1,5 \mu \mathrm{g} / \mathrm{mL}$ ) of MWCNTs for $24 \mathrm{~h}$. Then, a total of 20 $\mu 1$ alamarBlue (Thermo Fisher Scientific, Carlsbad, CA, USA) per well were added in wells and incubated with cells for $1 \mathrm{~h}$ at $37^{\circ} \mathrm{C}$ to reaction.

Also, the cell viability was confirmed with an xCELLigence RTDP system (ACEA Biosciences, San Diego, CA, USA). In brief, 2,500 cells/well were grew into E-plates and incubated at $37^{\circ} \mathrm{C}$ and $5 \% \mathrm{CO}_{2}$. After 6 hours, media with MWCNTs $(0.5 \mu \mathrm{g} / \mathrm{mL})$ was added into the wells. Then, all cells were incubated for a further 24 $\mathrm{h}$ to assess the cell viability. The high-content screening (HCS) multi-120 parameter cytotoxicity analyses were described as the previous study [29]. All tests were measured in triplicate, and the results were averaged.

\section{Cell cycle and apoptosis analysis}

Cell cycle and apoptosis analysis had been performed by flow cytometry (FCM). All cells were harvested with $0.25 \%$ trypsin/EDTA (Sigma-Aldrich, Saint Louis, MO, USA) after $24 \mathrm{~h}$ treatment and washed 
with cold PBS. To detect the cell apoptosis, cells were stained with propidium iodide (PI, Sigma-Aldrich, Saint Louis, MO, USA) and annexin V (Sigma-Aldrich, Saint Louis, MO, USA) for $15 \mathrm{~min}$ kept in dark place and were analysed by FACS Calibur Flow Cytometry (BD Biosciences, NJ, USA). To detect the cell cycles, cells were fixed with cold $75 \%$ ethanol (Sigma-Aldrich, Saint Louis, MO, USA) and stained with PI before quantified by FACS Calibur Flow Cytometry (BD Biosciences, NJ, USA). All tests were measured in triplicate.

\section{Reactive oxygen species (ROS) detection}

Reactive Oxygen Species Assay kit (Beyotime, Haimen, China) was used to detect cellular ROS. The cells were cultured in $10 \mathrm{~cm}$ dishes and treated with 0 and $0.5 \mu \mathrm{g} / \mathrm{mL}$ of MWCNTs. After $24 \mathrm{~h}$ treatment, cells were harvested and co-incubated with 2',7'-dichlorofluorescin diacetate (DCFH-DA) for $20 \mathrm{~min}$, and washed thrice with PBS and detected using FCM. Each experiment was performed at least twice.

\section{Western blot assay}

Total protein of cell line lysate (including control and $0.5 \mu \mathrm{g} / \mathrm{mL}$ of MWCNTs groups) was collected, and then separated on SDS-PAGE and transferred to polyvinylidene fluoride membranes (Millipore, Billerica, MA, USA). The antibodies used were anti-CDK4 (Cell Signaling Technology, 1:1000, Danvers, MA, USA), anti-Cyclin D1 (Cell Signaling Technology, 1:1000, Danvers, MA, USA), anti-Cyclin D3 (Cell Signaling Technology, 1:1000, Danvers, MA, USA), anti- ${ }_{53}$ (Cell Signaling Technology, $1: 1000$, Danvers, MA, USA), anti- $\beta$-actin (Beyotime, 1:1000, China). The immune complexes were detected by enhanced chemiluminescence (Millipore, Billerica, MA, USA). Blots were quantified by densitometry and normalized by use of $\beta$-actin to correct for differences in loading of the proteins. For densitometric analyses, the band was quantified using Image Lab software (BioRad laboratories, Hercules, CA, USA). Each experiment was performed at least twice.

\section{The uptake and distribution of MWCNTs in spermatocyte cell line}

After incubating in 6 well plates and treating with $0.5 \mu \mathrm{g} / \mathrm{mL}$ MWCNTs for $24 \mathrm{~h}$, cells were harvested with $0.25 \%$ trypsin/EDTA and fixed in $2.5 \%$ glutaraldehyde. Then cells were stained with lead citrate and uranyl acetate. Transmission electron microscopy (TEM) was used to detect the uptake and distribution of MWCNTs in cells.

\section{Long extension-polymerase chain reaction}

Long extension polymerase chain reaction (LXPCR) was performed as previously described [18]. In brief, genomic DNA in cells from each group was isolated with the DNA Isolation Kit (QIAGEN, 56304, Dusseldorf, German). The quantitation of the purified genomic DNA, as well as that of PCR products, was performed fluorometrically using the Quant-iT ${ }^{\mathrm{TM}}$ DNA Assay Kit (Life Technologies, Q-33120, CA, USA). PCR amplified products were performed by measuring fluorescence at $485 / 530 \mathrm{~nm}$ with the microplate reader (TECAN Infinite200 PRO). The four pairs of PCR primers employed in this study are given in Supplemental Table 1. The total input of genomic DNA was $15 \mathrm{ng}$ for each PCR reaction. To amplify the long fragment of $\mathrm{nDNA}$ (8.7 $\mathrm{kb})$, the thermocycler profile included initial denaturation at $94{ }^{\circ} \mathrm{C}$ for $1 \mathrm{~min}, 25$ cycles of $94{ }^{\circ} \mathrm{C} 15 \mathrm{~s}$, and $65^{\circ} \mathrm{C}$ for $12 \mathrm{~min}$, with final extension at $72{ }^{\circ} \mathrm{C}$ for $10 \mathrm{~min}$. For amplification of a long fragment of mtDNA (10.0 $\mathrm{kb}$ ), the standard thermocycler program included initial denaturation at $94{ }^{\circ} \mathrm{C}$ for $1 \mathrm{~min}, 20$ cycles of $94{ }^{\circ} \mathrm{C}$ for $15 \mathrm{~s}$, and $65{ }^{\circ} \mathrm{C}$ for $12 \mathrm{~min}$, with final extension at $72{ }^{\circ} \mathrm{C}$ for $10 \mathrm{~min}$. DNA damage was quantified by comparing the relative efficiency of amplification of large fragments of DNA (8.7 kb from nDNA and $10.0 \mathrm{~kb}$ from mtDNA) and normalizing this to the amplification of smaller $(6.5$ $\mathrm{kb}$ and $117 \mathrm{bp}$ ) fragments. Total DNA concentration was determined with Quant-iT ${ }^{\mathrm{TM}}$ DNA Assay Kit. Meanwhile, partial products were separated on a $2 \%$ agarose gel, stained with ethidium bromide. Each sample was run in triplicate, and each experiment was performed at least twice.

\section{ATP content assay}

ATP concentrations were determined using a luciferase-luciferin ATP Assay Kit (Beyotime, Haimen, China) according to the manufacturer's instructions. Protein concentration of the cells was measured using the BCA protein assay, and ATP content was adjusted to the protein concentration, resulted as $\mathrm{nmol} / \mathrm{mg}$ protein. Each experiment was performed at least thrice.

\section{Quantitative RT-PCR}

Total RNA was extracted from cells including control and MWCNTs treatment group using Trizol (Invitrogen, Carlsbad, CA), according to the manufacturer's instructions. Reverse transcription was performed using a Prime Script RT reagent kit (Takara, Dalian, China).

Real-time PCR reactions were performed with gene-specific primers and SYBR Green PCR Master 
Mix reagent kits (Takara, Dalian, China) using the ABI 7900 HT fast real-time system (Applied Bio systems, Foster City, CA). The specific primers were listed in Supplemental Table 1. All real-time PCR reactions were performed in triplicate, and the relative quantification in gene expression was determined using the $\Delta \Delta \mathrm{Ct}$ method, with calibration to control samples [30]. The housekeeping gene $18 S$ rRNA was used as an internal control. The levels of the genes were normalized relative to the expression levels of the gene $18 S$ rRNA. Each experiment was performed at least thrice.

\section{Oxygen consumption rate (OCR) measurements}

Cellular oxygen consumption was measured using a Seahorse XF96 Extracellular Flux analyzer (Seahorse Bioscience, North Billerica, MA). In briefly, cells were seeded in Seahorse XF96 cell culture microplates at a density of $1 \times 10^{4}$ cells per well and treated with 0 , and $0.5 \mu \mathrm{g} / \mathrm{mL}$ for $24 \mathrm{~h}$. Then, mitochondrial complex inhibitors were injected to all treatments sequentially in the following order: oligomycin $(1 \mu \mathrm{M})$, carbonyl cyanideptrifluoromethoxyphenylhydrazone (FCCP; $0.75 \mu \mathrm{M}$ ), and antimycin $\mathrm{A} /$ rotenone $(0.5 \mu \mathrm{M}$ each $)$, and the readings were taken after each inhibitor. OCR was automatically recorded by XF96 software. Rates were calculated per protein levels for control and MWCNTs treatment group.

\section{Data analysis}

Values are expressed as mean \pm standard deviation of the mean (S.D.) for all experiments. Non-parametric test and Kruskal-Waillis multiple comparison tests were used to analysis statistically significant differences between the treatments and the control. Statistical Analysis Systems statistical software package version 9.2 (SAS Institute, Inc.) was performed for all statistical analyses. A $P$ value $<0.05$ was designated as the cut-off for statistical significance. Bonferroni correction and FDR (false discovery rate) correction were performed to counteract the problem of multiple comparisons.

\section{ACKNOWLEDGMENTS}

This work is supported by the National Natural Science Foundation of China (Grant No.81172694 and No.81573174); the Outstanding Youth Fund of Jiangsu Province (SBK2014010296), the Research Project of Chinese Ministry of Education (213015A), the Priority Academic Program Development of Jiangsu Higher Education Institutions (PAPD), Qinglan project (JX2161015124), and the Flagship Major Development of Jiangsu Higher Education Institutions; and the Open Project Program of the State Key Laboratory of
Environmental Chemistry and Ecotoxicology (KF201501).

\section{CONFLICTS OF INTEREST}

The authors have declared that no competing interests exist.

\section{REFERENCES}

1. Klaine SJ, Alvarez PJ, Batley GE, Fernandes TF, Handy RD, Lyon DY, Mahendra S, McLaughlin MJ and Lead JR. Nanomaterials in the environment: behavior, fate, bioavailability, and effects. Environmental toxicology and chemistry / SETAC. 2008; 27:1825-1851.

2. Yang ST, Luo J, Zhou Q and Wang H. Pharmacokinetics, metabolism and toxicity of carbon nanotubes for biomedical purposes. Theranostics. 2012; 2:271-282.

3. Pacurari M, Qian Y, Fu W, Schwegler-Berry D, Ding M, Castranova V and Guo NL. Cell permeability, migration, and reactive oxygen species induced by multiwalled carbon nanotubes in human microvascular endothelial cells. Journal of toxicology and environmental health Part A. 2012; 75:112-128.

4. Deligianni DD. Multiwalled carbon nanotubes enhance human bone marrow mesenchymal stem cells' spreading but delay their proliferation in the direction of differentiation acceleration. Cell adhesion \& migration. 2014; 8:558-562.

5. Bottini M, Bruckner S, Nika K, Bottini N, Bellucci S, Magrini A, Bergamaschi A and Mustelin T. Multiwalled carbon nanotubes induce $\mathrm{T}$ lymphocyte apoptosis. Toxicology letters. 2006; 160:121-126.

6. Li JG, Li WX, Xu JY, Cai XQ, Liu RL, Li YJ, Zhao QF and Li QN. Comparative study of pathological lesions induced by multiwalled carbon nanotubes in lungs of mice by intratracheal instillation and inhalation. Environmental toxicology. 2007; 22:415-421.

7. Visalli G, Bertuccio MP, Iannazzo D, Piperno A, Pistone A and Di Pietro A. Toxicological assessment of multi-walled carbon nanotubes on A549 human lung epithelial cells. Toxicology in vitro : an international journal published in association with BIBRA. 2015; 29:352-362.

8. Lindberg HK, Falck GC, Suhonen S, Vippola M, Vanhala E, Catalan J, Savolainen K and Norppa H. Genotoxicity of nanomaterials: DNA damage and micronuclei induced by carbon nanotubes and graphite nanofibres in human bronchial epithelial cells in vitro. Toxicology letters. 2009; 186:166-173.

9. Migliore L, Saracino D, Bonelli A, Colognato R, D'Errico MR, Magrini A, Bergamaschi A and Bergamaschi E. Carbon nanotubes induce oxidative DNA damage in RAW 264.7 cells. Environmental and molecular mutagenesis. 2010; 51:294-303. 
10. Nagai H, Okazaki Y, Chew SH, Misawa N, Yamashita Y, Akatsuka S, Ishihara T, Yamashita K, Yoshikawa Y, Yasui H, Jiang L, Ohara H, Takahashi T, Ichihara G, Kostarelos $\mathrm{K}$, Miyata $\mathrm{Y}$, et al. Diameter and rigidity of multiwalled carbon nanotubes are critical factors in mesothelial injury and carcinogenesis. Proceedings of the National Academy of Sciences of the United States of America. 2011; 108:E1330-1338.

11. Clift MJ, Endes C, Vanhecke D, Wick P, Gehr P, Schins RP, Petri-Fink A and Rothen-Rutishauser B. A comparative study of different in vitro lung cell culture systems to assess the most beneficial tool for screening the potential adverse effects of carbon nanotubes. Toxicological sciences. 2014; 137:55-64.

12. Chen T, Zang J, Wang H, Nie H, Wang X, Shen Z, Tang $\mathrm{S}$, Yang $\mathrm{J}$ and Jia G. Water-soluble taurine-functionalized multi-walled carbon nanotubes induce less damage to mitochondria of RAW 264.7 cells. Journal of nanoscience and nanotechnology. 2012; 12:8008-8016.

13. Chen B, Liu Y, Song WM, Hayashi Y, Ding XC and Li WH. In vitro evaluation of cytotoxicity and oxidative stress induced by multiwalled carbon nanotubes in murine RAW 264.7 macrophages and human A549 lung cells. Biomedical and environmental sciences : BES. 2011; 24:593-601.

14. Coccini T, Manzo L and Roda E. Safety evaluation of engineered nanomaterials for health risk assessment: an experimental tiered testing approach using pristine and functionalized carbon nanotubes. ISRN toxicology. 2013; 2013:825427.

15. Bai Y, Zhang Y, Zhang J, Mu Q, Zhang W, Butch ER, Snyder SE and Yan B. Repeated administrations of carbon nanotubes in male mice cause reversible testis damage without affecting fertility. Nature nanotechnology. 2010; 5:683-689.

16. Wang X, Xia T, Ntim SA, Ji Z, George S, Meng H, Zhang $\mathrm{H}$, Castranova V, Mitra S and Nel AE. Quantitative techniques for assessing and controlling the dispersion and biological effects of multiwalled carbon nanotubes in mammalian tissue culture cells. ACS nano. 2010; 4:72417252 .

17. Ali-Boucetta H, Al-Jamal KT and Kostarelos K. Cytotoxic assessment of carbon nanotube interaction with cell cultures. Methods Mol Biol. 2011; 726:299-312.

18. Furda A, Santos JH, Meyer JN and Van Houten B. Quantitative PCR-based measurement of nuclear and mitochondrial DNA damage and repair in mammalian cells. Methods Mol Biol. 2014; 1105:419-437.

19. Schon EA, DiMauro S and Hirano M. Human mitochondrial DNA: roles of inherited and somatic mutations. Nature reviews Genetics. 2012; 13:878-890.

20. Siegrist KJ, Reynolds SH, Kashon ML, Lowry DT, Dong C, Hubbs AF, Young SH, Salisbury JL, Porter DW, Benkovic SA, McCawley M, Keane MJ, Mastovich JT, Bunker KL, Cena LG, Sparrow MC, et al. Genotoxicity of multi-walled carbon nanotubes at occupationally relevant doses. Particle and fibre toxicology. 2014; 11:6.

21. Tilton SC, Karin NJ, Tolic A, Xie Y, Lai X, Hamilton RF, Jr., Waters KM, Holian A, Witzmann FA and Orr G. Three human cell types respond to multi-walled carbon nanotubes and titanium dioxide nanobelts with cellspecific transcriptomic and proteomic expression patterns. Nanotoxicology. 2014; 8:533-548.

22. Zhu L, Chang DW, Dai L and Hong Y. DNA damage induced by multiwalled carbon nanotubes in mouse embryonic stem cells. Nano letters. 2007; 7:3592-3597.

23. Mecocci P, MacGarvey U, Kaufman AE, Koontz D, Shoffner JM, Wallace DC and Beal MF. Oxidative damage to mitochondrial DNA shows marked age-dependent increases in human brain. Annals of neurology. 1993; 34:609-616.

24. Papanicolaou KN, Ngoh GA, Dabkowski ER, O'Connell KA, Ribeiro RF, Jr., Stanley WC and Walsh K. Cardiomyocyte deletion of mitofusin-1 leads to mitochondrial fragmentation and improves tolerance to ROS-induced mitochondrial dysfunction and cell death. American journal of physiology Heart and circulatory physiology. 2012; 302:H167-179.

25. Godley BF, Shamsi FA, Liang FQ, Jarrett SG, Davies S and Boulton M. Blue light induces mitochondrial DNA damage and free radical production in epithelial cells. The Journal of biological chemistry. 2005; 280:21061-21066.

26. Mihalchik AL, Ding W, Porter DW, McLoughlin C, Schwegler-Berry D, Sisler JD, Stefaniak AB, SnyderTalkington BN, Cruz-Silva R, Terrones M, Tsuruoka S, Endo M, Castranova V and Qian Y. Effects of nitrogendoped multi-walled carbon nanotubes compared to pristine multi-walled carbon nanotubes on human small airway epithelial cells. Toxicology. 2015; 333:25-36.

27. Zhu Y, Ran T, Li Y, Guo J and Li W. Dependence of the cytotoxicity of multi-walled carbon nanotubes on the culture medium. Nanotechnology. 2006; 17:4668-4674.

28. Wang Z, Xu Y, Meng X, Watari F, Liu H and Chen X. Suppression of c-Myc is involved in multi-walled carbon nanotubes' down-regulation of ATP-binding cassette transporters in human colon adenocarcinoma cells. Toxicology and applied pharmacology. 2015; 282:42-51.

29. Xu B, Chen M, Ji X, Mao Z, Zhang X, Wang X and Xia Y. Metabolomic profiles delineate the potential role of glycine in gold nanorod-induced disruption of mitochondria and blood-testis barrier factors in TM-4 cells. Nanoscale. 2014; 6:8265-8273.

30. Ferreira ID, Rosario VE and Cravo PV. Real-time quantitative PCR with SYBR Green I detection for estimating copy numbers of nine drug resistance candidate genes in Plasmodium falciparum. Malaria journal. 2006; $5: 1$. 